\title{
THE TOP 101 CITED ARTICLES IN ENVIRONMENTAL CLEAN-UP: OIL SPILL REMEDIATION
}

\author{
DADRASNIA A. ${ }^{1}$ \\ SHAHSAVARI N. ${ }^{2}$ \\ SALMAH I. ${ }^{1, *}$
}

\author{
${ }^{1}$ Institute of Biological Sciences, Faculty of Science \\ University of Malaya, 50603 Kuala Lumpur, Malaysia \\ Hajiabad Branch, Islamic Azad University \\ Hajiabad, Hormozgan, 55773, Iran
}

Received: 09/07/2014

Accepted: 05/10/2015

Available online: 05/10/2015 *to whom all correspondence should be addressed: e-mail: salmah r@um.edu.my

\section{ABSTRACT}

The aim of this search was to identify the 101 top cited articles in the field of oil spill remediation. A search was conducted based on a database of the Web of Science included the journal citation reports from 1980 to 2013. The number of citations of the first 101 top cited articles is from 24 to 816 . The decades with most top-cited articles published were 2000-2009 (47 articles) and 1990-1999 (37 articles). The most common research area of study was environmental science ecology. All the articles were published in 54 different journals in this category. Journals with the highest number of cited articles were Applied and Environmental Microbiology (10 articles), Environmental Science and Technology (6 articles), Organic Geochemistry (6 articles), Chemosphere ( 5 articles). Among the top cited articles the mostly named author were Sakkata Y, and Uddin MA with 6 of articles, followed by Fedorak PM with 5. Out of 101 top cited articles, 14, 13 and 12 articles originated from Canada, USA and France, respectively. Okayama and Alberta Universities were the most common productive institutions. Based on our knowledge, this is the first report of the 101 top cited articles in this category.

Keywords: Top cited articles, ISI web of knowledge, Journals, Science, Oil degradation

\section{Introduction}

Modern industrial society is built and ruled by petroleum hydrocarbons. There is a rapid rise in petroleum consumption and as a result, annually huge amounts of hydrocarbons are discharged into the environment, either accidentally or deliberately. Oil spillage has been a common problem with shell companies, nations and our environment; however, this issue going to be a significant source of oil pollution in water and soil (Bolliger, 2000). Therefore, after having a full-fledged case study of oil spills, we are able to come up with a suitable solution to remediation of pollution. During the recent decade there is a concern about the issues as evidenced from increasing impact of environmental science journals and citation analysis (Khan and Ho, 2012).

The number of times cited an article that published and has been cited by other authors is known as a one of the common methods for evaluating the academic importance of a paper and identify those researchers who have made high impact in a specific area of knowledge, over time (Moed, 2009). So, the one most cited article can made considered as the best manuscript (Ho, 2012). Analysis of the most frequently cited articles may illustrate the effect of works of colleagues and provide a historical view on the scientific progress in the field of specialty (Norio et al., 2007). However, the number of citations which 
an article received will describe the capacity of the article and impact character to generate changes in discussion and further research (Lefaivre et al., 2011). Citation analysis as well, can help to indentify leaders among countries or institutions. At the individual level, name order of the authors shows that the first listed author who contributed more to work, writing of the manuscript and research (Kempers, 2002; Engers et al., 1989).

It has been accepted that the corresponding author is the most important positions, whom very often is the first and the last (Costas and Bordons 2011). In contrast, recent articles may not have had sufficient publication time to get high citation levels. There is no index to determine whether an article is more useful for other authors or to researchers who need to be cited in order to achieve personal promotion or financial support (Feijoo et al., 2013).

The institute of scientific information (ISI) has compiled the most relevant bibliometric information of published scientific articles, since 1945 until now. While the science citation index as a tool to quantify citations, was not initiated until 1962. Recently this resource is called "Science Citation Index Expanded" and that is a form of Web of Science section (STR, 2014).

Based on our knowledge this article is the first study that has reported the top cited articles in the field of the environmental remediation. This review is an attempt to identify the 101 articles related to oil spill remediation analyzed with regards to total citations, authors, centuries and institutions to help scholars and researchers to determine areas of research in this field that have been extensively addressed as well as the gaps that should be addressed.

\section{Methods}

A search for all articles relevant to "oil spill remediation" was conducted through the ISI Web of Knowledge database because this study only aimed to search for articles dealing with remediation and relevant issues. Online version of Science Citation Index Expanded (SCIE), accessed via Web of Science was adopted as the citation database. The following keywords were used to find articles (Fig 1).

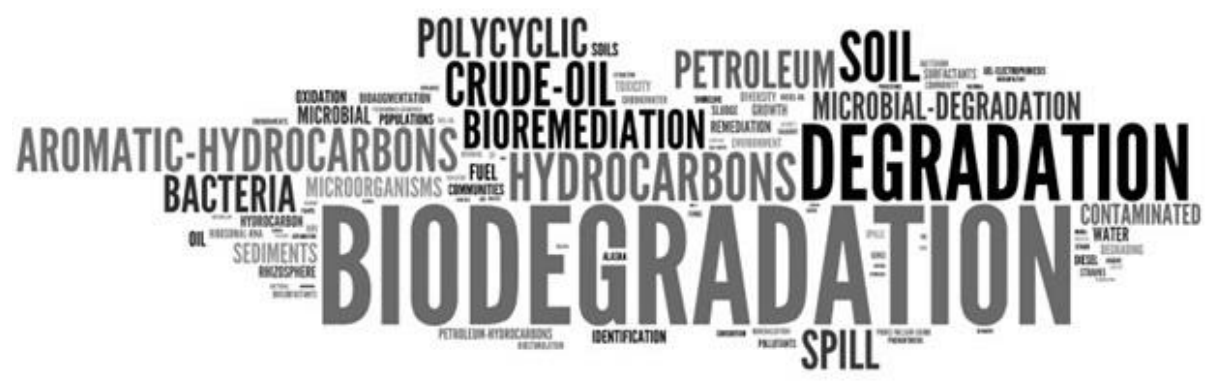

Figure 1. Keywords found from articles

The search results were filtered to exclude papers related to oil spill remediation. Proceedings paper was excluded by refinement. The articles published from 1980 to 2013 were retrieved. Table 1 shows the distribution of 7 document types. However, in this paper, review and articles were considered. The final filtered papers were ranked according to Journal Citation Reports (JCR), from highest to least cited on January 2014. The first 101 papers were selected and inputted into an Excel spreadsheet.

Several articles were cited more often than others because of the difference in time since publication. A citation index was also determined for each article to control this error. The citation index was defined as the mean number of citation times per year (Loonen et al., 2008). The 101 articles were then identified based on the number of citations and citation index value. The articles were classified based on article specifications, such as publication date, journal name, title, authors' names, organization, and country. The data collection method was categorized as a retrospective, prospective, cross-sectional, and longitudinal. The research design was likewise defined to be qualitative, quantitative or mixed mode. 
Statistical analysis was performed using SPSS 19 (SPSS Inc., Chicago, IL). Nonparametric test of Kruskal Wallis was used to compare the differences with a confidence level of .05 .

Table 1. Record count of document types

\begin{tabular}{ccc}
\hline Document types & No. of documents & Percentage (\%) \\
\hline Article & 573 & 88.83 \\
\hline Meeting abstract & 44 & 6.82 \\
\hline Proceeding paper & 41 & 6.35 \\
\hline Review & 14 & 2.17 \\
\hline Editorial material & 6 & 0.93 \\
\hline Correction & 3 & 0.46 \\
\hline Book review & 2 & 0.31 \\
\hline
\end{tabular}

\section{Results}

\subsection{Citation, sources and year}

Analysis of citation count provides the most frequently cited journals and articles (Nason et al., 2013). That shows the quantitative information about the areas of research, high impact journals and authors. One hundred and one selected first top articles were published from 1981 to 2013 with a citation range of 24 to 816 times since publication, with the average citation rate of 88.44 times. Among the 101 articles, 10 were from Applied and Environmental Microbiology, 6 from Journal of Environmental Science and Technology/ Journal of Organic Chemistry, 5 from Chemosphere, and 4 from Journal of Canadian Journal of Microbiology / Marine Pollution Bulletin / Water Air and Soil Pollution. The highest number of articles (10) was published in 2002. More articles were published from 2000 to 2009 compared with that in 1990 to 1999. However, 16 and 47 articles were published from 1980 to 1989 and 2000 to 2009, respectively. According to the web of science categories, $43 \%$ were published in the environmental science category, followed by biotechnology applied microbiology (21\%), engineering; environmental microbiology (15\%), and engineering chemical (10\%). The rest of the category covered less than $10 \%$. Table 2 demonstrates the most frequently article published in the field of oil spill remediation with more than 100 times cited. Out of these 15 articles, twelve (81.2\%) was published in 1990s, two (12.5\%) in 1981 and one was published in 2002. The journals in which these articles published were Applied and Environmental Microbiology (IF $2012=3.67$ ) with four articles, Environmental Science \& Technology (IF $2012=5.25$ ) with three articles, Microbiological Reviews (since 1997 the name of journal has been changed as "Microbiology and Molecular Biology Reviews", IF $2012=16.41$ ) with two articles followed by Nature (IF $2012=38.59$ ), Journal of Chemical Technology and Biotechnology (IF $2012=2.5$ ), Marine Pollution Bulletin (IF $2012=2.53$ ), Journal of Hazardous Materials (IF $2012=3.92$ ), Canadian Journal of Microbiology (IF $2012=1.19$ ), Geochimica et Cosmochimica Acta (IF $2012=3.88$ ) with $\mathrm{n}=1$ each. Among them, a highly cited article (816 times cited) was published in Microbiological Reviews in 1981, while Applied and Environmental Microbiology has the most top cited articles in the list. The second highly cited article with 330 times was published in Applied and Environmental Microbiology in 1999 and the least citations (101 times cited) was published in 1994. The latest top-cited articles was "microbial-degradation of marine evaporitic crude oils" published in 1991 by Grimalt J.O. et al., with total citation of 24 times cited. The research area of top-cited articles was classified into 37 different fields. The major area was biotechnology followed by geochemistry and engineering.

"Time effect" serve as one of the parameters for citation analysis and known as a shortcoming of the citation [6]. According to time affect for the six top-cited articles (Fig 2), the most articles being at disadvantage. In year 2011, Atlas (1981) gains the highest number of citation, follow by Macnaughton et al., (1999) compare to other articles. While in year 1999 Bragg et al., (1994) is the highly cited article, however, it is at the bottom among the top cited in 2005 and 2009. This illustrates a clear role of time 
from the year of publication. Notwithstanding research quality, experimental setups and analysis techniques are improving; newly published articles are seated on the back of citation analysis.

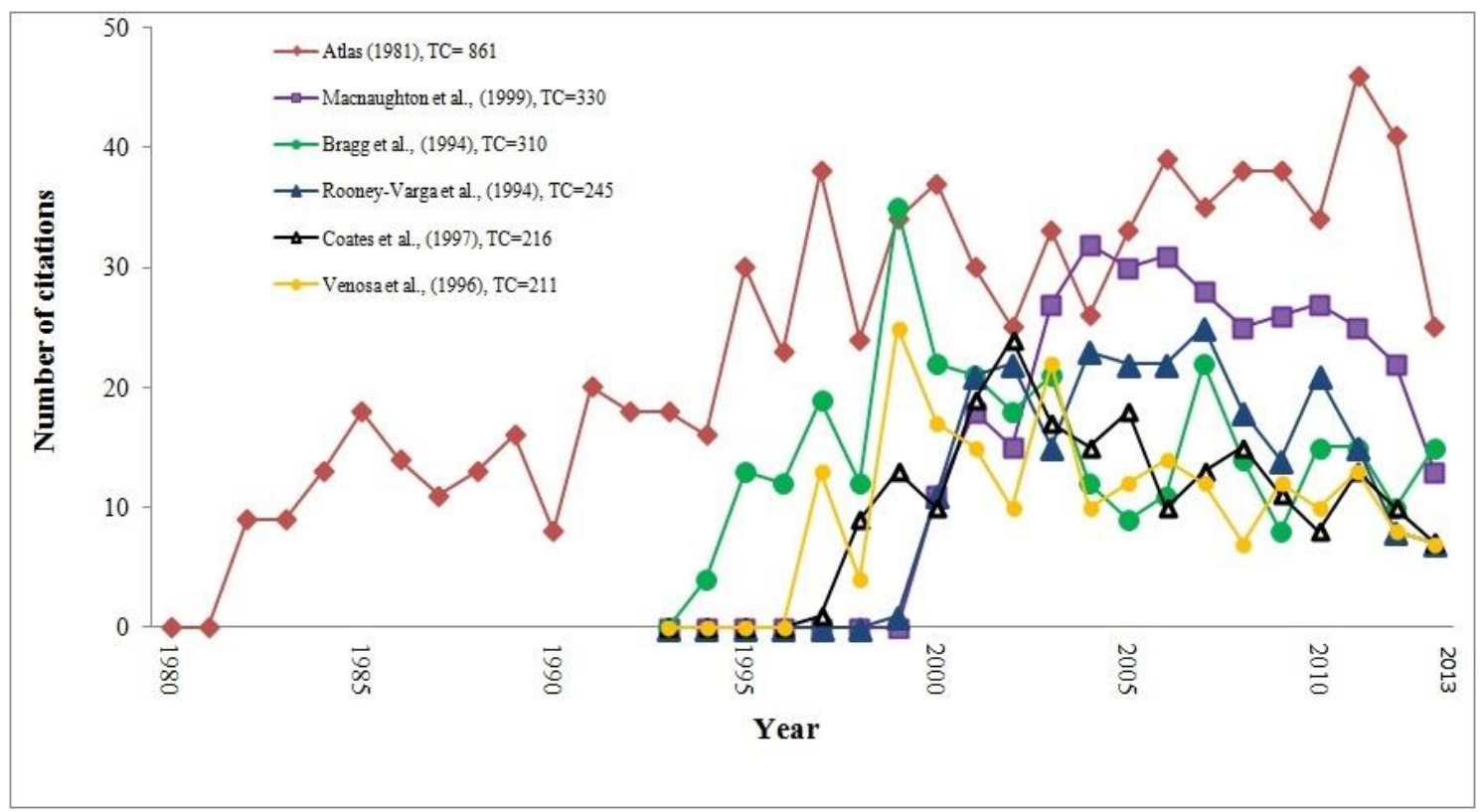

Figure 2. Time effect on top-cited articles

As seen in Figure 3, about $45.5 \%$ of articles were published in 2000 s followed by $37.6 \%$ in $1990 \mathrm{~s}$. In addition, it shows that in earlier decades, top cited articles have higher citations, while on average published fewer top cited articles compare to recent decades. Figure 4 shows the distribution of the first 101 top cited articles from 19981 to 2011. The statistical analysis does not show any significantly difference and correlation between time and number of top articles published in year. Ten top cited articles were published in the year 2002; while in 1996 were eight articles. However, on average, three top cited articles were published annually. In addition, no article was published under this consideration in the year 1982, 1987, 1989 and 2010.

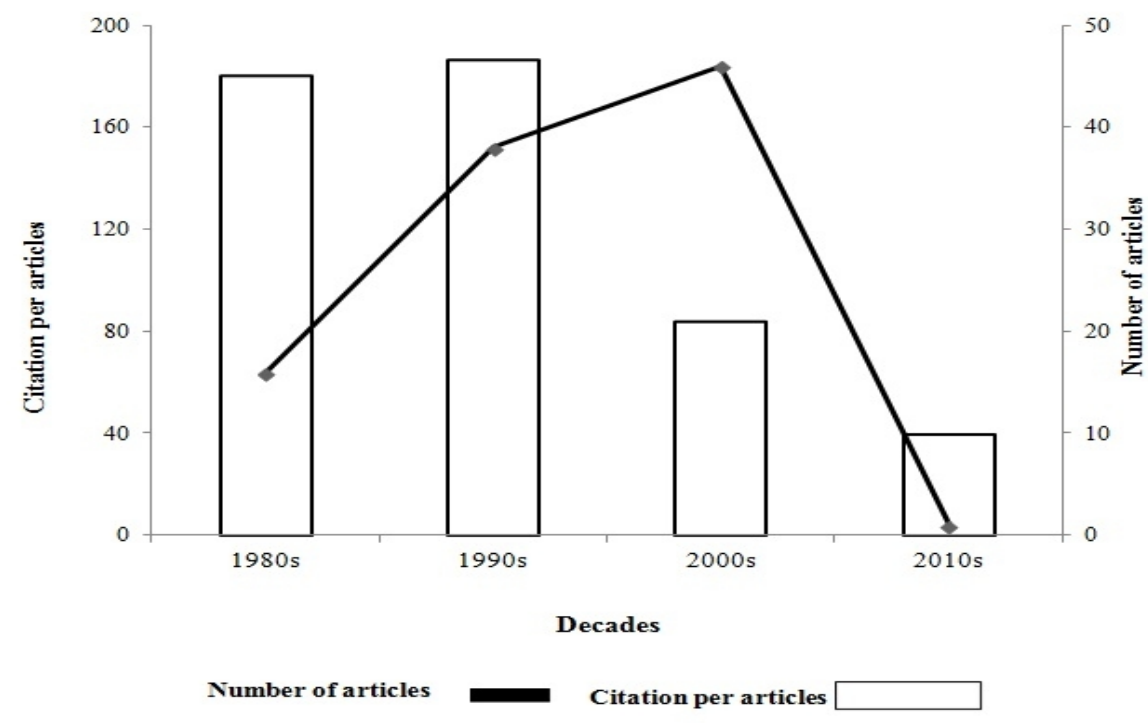

Figure 3. Number of citations per articles and top cited articles by decade of publication 
Table 2. The most frequently cited articles

\begin{tabular}{|c|c|c|}
\hline Citation information & TC 2013>100 & C2013 \\
\hline $\begin{array}{l}\text { Atlas R.M. (1981), Microbial-degradation of petroleum-hydrocarbons- an } \\
\text { environmental perspective, Microbiological Reviews, 45(1), 180-209. }\end{array}$ & 816 & 25 \\
\hline $\begin{array}{l}\text { Macnaughton S.J., Stephen J.R., Venosa A.D., Davis G.A., Chang Y.J. and White } \\
\text { D.C. (1999), Microbial population changes during bioremediation of an } \\
\text { experimental oil spill, Applied and Environmental Microbiology, 65(8), 3566- } \\
3574 .\end{array}$ & 330 & 13 \\
\hline $\begin{array}{l}\text { Bragg J.R., Prince R.C., Harner E.J. and Atlas R.M. (1994), Effectiveness of } \\
\text { bioremediation for the exxon-valdez oil-spill, Nature, 368, 413-418. }\end{array}$ & 310 & 15 \\
\hline $\begin{array}{l}\text { Rooney-Varga J.N., Anderson R.T., Fraga J.L., Ringelberg D. and Lovley D.R. } \\
\text { (1999), Microbial communities associated with anaerobic benzene degradation } \\
\text { in a petroleum-contaminated aquifer, Applied and Environmental Microbiology, } \\
65,3056-3063 \text {. }\end{array}$ & 245 & 7 \\
\hline $\begin{array}{l}\text { Coates J.D., Woodward J., Allen J., Philp P. and Lovley D.R. (1997), Anaerobic } \\
\text { degradation of polycyclic aromatic hydrocarbons and alkanes in petroleum- } \\
\text { contaminated marine harbor sediments, Applied and Environmental } \\
\text { Microbiology, 63, 3589-3593. }\end{array}$ & 216 & 7 \\
\hline $\begin{array}{l}\text { Venosa A.D., Suidan M.T., Wrenn B.A., Strohmeier K.L., Haines J.R., Eberhart B.L., } \\
\text { King D. and Holder E. (1996), Bioremediation of an experimental oil spill on the } \\
\text { shoreline of Delaware bay, Environmental Science \& Technology, 30, 1764-1775. }\end{array}$ & 211 & 7 \\
\hline $\begin{array}{l}\text { Swannell R.P., Lee K. and McDonagh M. (1996), Field evaluations of marine oil } \\
\text { spill bioremediation, Microbiological Reviews, 60, 342-365. }\end{array}$ & 177 & 6 \\
\hline $\begin{array}{l}\text { Roling W.F.M., Milner M.G., Jones D.M., Lee K., Daniel F. and Swannell R.J.P. and } \\
\text { Head I.M. (2002), Robust hydrocarbon degradation and dynamics of bacterial } \\
\text { communities during nutrient-enhanced oil spill bioremediation, Applied and } \\
\text { Environmental Microbiology, 68, 5537-5548. }\end{array}$ & 170 & 14 \\
\hline $\begin{array}{l}\text { Pritchard P.H. and Costa C.F. (1991), Epas alaska oil-spill bioremediation project, } \\
\text { Environmental Science \& Technology, 25, 372-379. }\end{array}$ & 147 & 1 \\
\hline $\begin{array}{l}\text { Salanitro J.P., Dorn P.B., Huesemann M.H., Moore K.O., Rhodes I.A., Jackson } \\
\text { L.M.R., Vipond T.E., Western M.M. and Wisniewski H.L. (1997), Crude oil } \\
\text { hydrocarbon bioremediation and soil ecotoxicity assessment, Environmental } \\
\text { Science \& Technology, 31, 1769-1776. }\end{array}$ & 133 & 4 \\
\hline $\begin{array}{l}\text { Atlas R.M. (1991), Microbial hydrocarbon degradation - bioremediation of oil- } \\
\text { spills, Journal of Chemical Technology and Biotechnology, 52, 149-156. }\end{array}$ & 128 & 6 \\
\hline $\begin{array}{l}\text { Atlas R.M. (1995), Petroleum biodegradation and oil spill bioremediation, Marine } \\
\text { Pollution Bulletin, 31, 178-182. }\end{array}$ & 115 & 8 \\
\hline $\begin{array}{l}\text { Watts R.J. and Dilly S.E. (1996), Evaluation of iron catalysts for the Fenton-like } \\
\text { remediation of diesel-contaminated soils, Journal of Hazardous Materials, 51, } \\
\text { 209-224. }\end{array}$ & 110 & 3 \\
\hline $\begin{array}{l}\text { Fedorak P.M. and Westlak D.W.S. (1981), Microbial-degradation of aromatics } \\
\text { and saturates in Prudhoe bay crude-oil as determined by glass-capillary gas- } \\
\text { chromatography, Canadian Journal of Microbiology, } 27,432-443 .\end{array}$ & 104 & 1 \\
\hline $\begin{array}{l}\text { Cozzarelli I.M., Baedecker M.J., Eganhouse R.P. and Goerlitz D.F. (1994), The } \\
\text { geochemical evolution of low-molecular-weight organic-acids derived from the } \\
\text { degradation of petroleum contaminants in groundwater, Geochimica et } \\
\text { Cosmochimica Acta, 58, 863-877. }\end{array}$ & 101 & 6 \\
\hline $\begin{array}{l}\text { TC } 2013 \text { > 100: number of citations more than } 100 \text { till 2013; C 2013: number of } \\
\text { citations in } 2013\end{array}$ & & \\
\hline
\end{tabular}




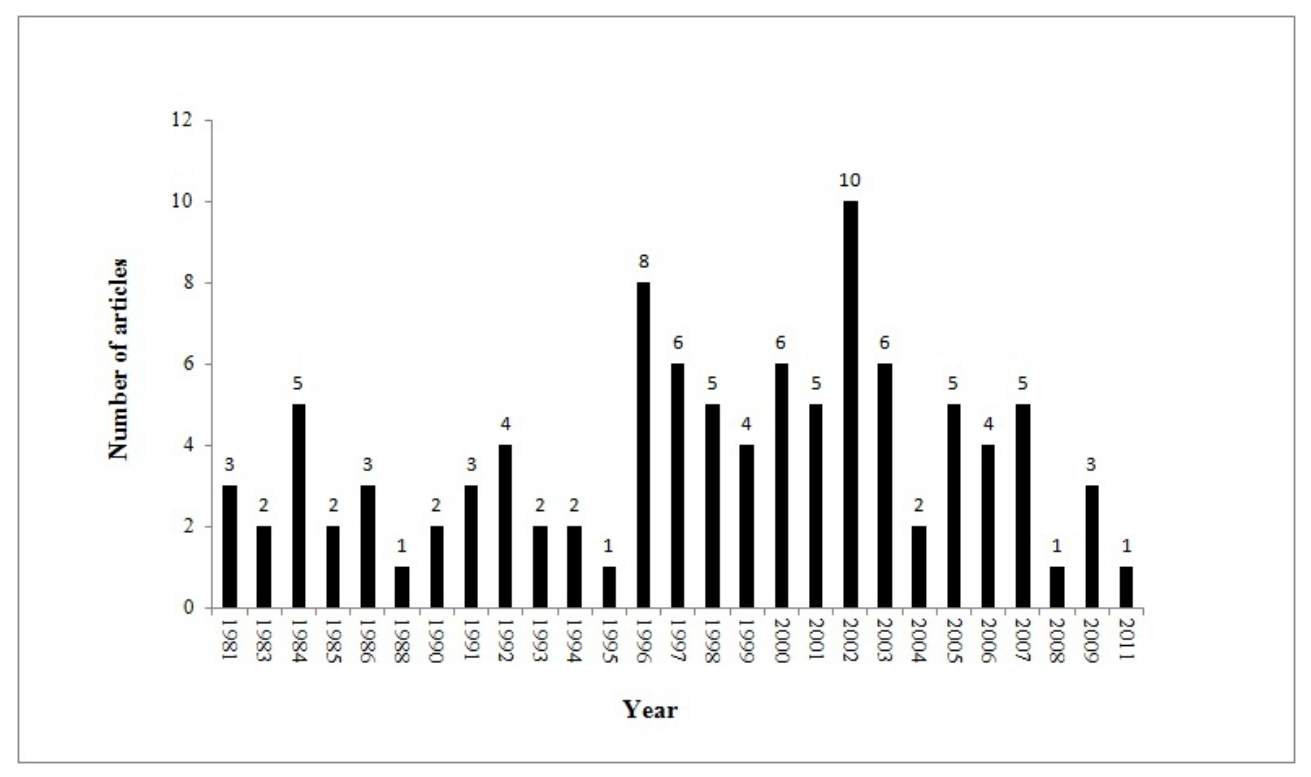

Figure 4. Distribution of 101 top-cited articles from 1981 to 2011

\subsection{Countries and authors of origin of the top 101 cited articles}

The publication provided by different countries is estimated based on the location of affiliation of the one author of the top articles. Then the countries were ranked according to the number of total top cited articles (Table 3). The data presents that the most productive authors are from Canada with 14 articles followed the United States of America, France and Japan with 13, 12 and 9 top cited articles, respectively. There are many reasons behind the influence of the countries on a number of publications such as large area of research in their country; their higher research funds might be probable reasons. For instance, American journals are preferred to citing American articles which can be the reason for their dominance in this field (Khan and Ho, 2012).

Table 3. Countries of 101 top cited articles

\begin{tabular}{cccc}
\hline Country & NO. of articles & Country & NO. of articles \\
\hline Canada & 13 & Romania & 1 \\
\hline France & 12 & Tunisia & 1 \\
\hline United states & 12 & Algeria & 1 \\
\hline England & 11 & Austria & 1 \\
\hline Japan & 10 & Brazil & 1 \\
\hline Germany & 8 & Denmark & 1 \\
\hline Spain & 7 & Finland & 1 \\
\hline Italy & 5 & Greece & 1 \\
\hline Norway & 2 & Kuwait & 1 \\
\hline Poland & 2 & Portugal & 1 \\
\hline Australia & 2 & Switzerland & 1 \\
\hline India & 2 & Texas & 1 \\
\hline China & 2 & Turkey & 1 \\
\hline
\end{tabular}

Affiliation of at least one the author was used to estimate the contribution of the different institutions. Among the first 101 top-cited articles, Okayama University and University of Alberta were the most productive institutes with four articles followed by CSIC Department of Molecular Microbiology in Spain with three top-cited articles. Based on web of science information, $44 \%$ of the 101 top cited articles were single institution publications and $56 \%$ were collaborative publications. 23 articles were attributed to five authors and 22 articles to two authors, while the number articles with one author is 3 publications. Among 101 top-cited articles, the top five productive authors are shown in Table 4. In other word, in quantitative 
terms, the authors with the most number of publications was Sakata, Y. with six articles and 305 times citations followed by Fedorak P. M. and Emsley, A.M. with five and three articles, respectively.

Table 4. Top 5 most productive authors

\begin{tabular}{lcccc}
\multicolumn{1}{c}{ Author } & TP & FA & CoA & TC 2013 \\
\hline Sakata Y. & 6 & 2 & 4 & 305 \\
\hline Fedorak P.M. & 5 & 5 & 0 & 256 \\
\hline Emsley A.M & 3 & 3 & 0 & 199 \\
\hline Roling W.F.M & 2 & 2 & 0 & 267 \\
\hline Rambeloarisoa & 2 & 2 & 0 & 97 \\
\hline
\end{tabular}

\section{Discussion}

This study analysed the 101 most influential articles on disciplinary oil spill remediation techniques work journals published over the previous decade. There is no agreed upon criteria exist for selecting such journals (Thyer, 2001). Generally, in every discipline, a number of studies have a significant impact on the development of a given discipline because they provide the basis for new procedures, methods, or concepts. Articles with the highest impact were obtained by counting the citation (ISI web of knowledge does not exclude self-citing) (Dumont, 1986; Ponce and Lozano 2010). Through a systematic citation analysis, the current study aimed to identify scientific works in the remediation area. In addition, the journal citation report (ISI Web of Knowledge) as a dynamic database in which the journals are updated annually in each category. As a result, some of the articles with high number of citations which have been published in ISI journals may exclude, if the journals are not longer in ISI category. The journal impact factor is one of the known measures that measure a journal's significance within the corresponding field (Garfield, 1982). In the current study, the journals were obtained from various fields, and the majority of which were from the field of Environmental Science followed by Biotechnology \& Applied Microbiology; Geochemistry \& Geophysics; Engineering; Environmental Sciences \& Ecology; Agriculture; Chemistry; Food Science \& Technology; Biochemistry \& Molecular Biology; Science \& Technology.

Although we were expecting a higher number, only $2 \%$ of the papers were review articles, whereas majority included original research articles (88\%). These results are in contrast with the general belief that review articles had the highest number of citations (Dubin et al., 1993). Our findings are consistent with those of previous studies on top cited articles in other fields (Baltussen and Christoph, 2004; Hennessey et al., 2009). The findings might be associated with a preference for referring to experimental evidence rather than review articles or expert opinion. The six-year span of 1996 to 2003 had the highest number of top cited articles. The least number of articles were published in the 2010 to 2013 and 1980s with 1 and 18 articles, respectively. The citation rate has gradually risen over the last decade. This increase would seem logical because scientific papers are usually cited one or two years after publication and reach peak citation about 10 years after publication (Eshraghi et al., 2013).

The chronological trend of top cited articles is in accordance with previous findings, and the results indicate that the peak recognition of important papers in a field can be obtained in a 10- to 20-year period (Albert, 1988). None of the top cited articles came from Asia, and the majority originated from England, Canada and the United States. No relationship between country and citation was observed, which indicates that a study does not necessarily have to originate from a particular country for it to become top cited. The subject of an article which published in a journal shows the interest of the authors and tendency of the editorial board. However, the citation rate of an article represents its influence on the readers.

Result of publication countries analysis shows that England was published $(n=38)$ articles followed by United State $(n=29)$, Netherlands $(n=16)$, Germany $(n=4)$ and the rest of the countries had less than 3 publications. Also, Hundred of articles were published in English language and only one paper (rank = 82) 
was published in the French language in journal of Revue Française Des Corps Gras in 1987 with 26 times citation.

\subsection{Limitations of present study}

We recognize that our study has some possible methodological limitations. First, the journals have dissimilar attitudes to accept or reject a submitted manuscript. Therefore, specific journals could have stricter choice standards that might have affected the applicability or quality of their publications. The criteria might be a cause why most top cited papers were found in one journal.

Second, challenges and problems might arise from citation counts, such as ignoring potential citations in book chapters, considering self-citations, peers' preference to cite papers from the journal they submit their work, and preference to cite review articles or full-length articles. The quality of a work is best recognized by citation count and is a superior measure of an author's impact and originality of work compared with article counts (Bohannon and Dave 1991). Next, chronological bias is possible in the current citation analysis because older articles can still be cited more often regardless of factual impact; whiles articles published more recently had inadequate time to have high citation rates. As a result, lately published articles might have been underestimated in terms of their impact (Bohannon and Dave 1991). Thus, the probability of biases in citing a given article as a result of tendency to cite papers by colleagues, well-known authors, or reviewers should be acknowledged.

\section{Conclusions}

This study might be considered as the first report on the scientific papers in oil spill remediation. The findings represent that studies written in English mainly focused on remediation field and published in ISI journals are the most likely papers to be cited in this field. The articles had qualitative method. The results imply that the rate of citation does not necessarily determine the importance or impact of a specific publication.

\section{Acknowledgments}

The authors would like to acknowledge the support of OCAR chancellery of University Malaya with grant numbers A-21010-DA674 and A- 21010-DA677 and also UMRP with grant number RP023A-14AFR. Also, the authors would like to thank Mr. Hossein Jamali for his invaluable assistance on the statistics.

\section{References}

Albert D.M. (1988), Analysis of the Archives' most frequently cited articles, Arc Ophth, 106, 465.

Baltussen A. and Christoph H.K. (2004), Citation classics in anesthetic journals, Anesth Analg, 98, 443-451.

Bohannon R.W. and Dave R. (1991), Core journals of rehabilitation: identification through index analysis, Int. J. Rehabilitation Research, 14, 333-336.

Bolliger C. (2000), Bioremediation of a Heating Oil-Contaminated Aquifer - Quantification of Processes by Chemical, Biological, and Stable Isotope Analyses, Doctor of Natural science, ETH Zürich, 160 pages.

Costas R. and Bordons M. (2011), Do age and professional rank influence the order of authorship in scientific publications? Some evidence from a micro-level perspective, Scientometics, 88,145-161.

Dubin D., Arthur W.H. and Kenneth A.A. (1993), Citation classics in clinical dermatologic journals: citation analysis, biomedical journals, and landmark articles, 1945-1990. Arch Dermatol, 129: 1121-9.

Dumont J.E. (1989), The bias of citations, Trends Biochem Sci., 14, 327-328.

Eshraghi A., Abu Osma N.A., Gholizadeh H., Ali S. and Shadgan B. (2013), 100 top-cited scientific papers in limb prosthetics, BioMed. Eng., 12, 119.

Engers M., Gans J.S., Grant S. and King S.P. (1989), First author conditions, J. Polit. Econ, 107, 859-883.

Feijoo F.J., Limeres J., Fernández-Varela M., Ramos I. and Diz P. (2013), The 100 most cited articles in dentistry, Clin Oral Invest, 18, 699-706. 
Garfield E. (1982), Data from Arts and Humanities Citation Index reveal the interrelationships of science and humanities, Current Contents, 46, 5-7.

Hennessey K., Kourosh A. and Andrew E.M. (2009), The top 100 cited articles in urology, Can. Urol. Assoc. J, 3, 293.

Ho Y.S. (2012), Top-cited Articles in Chemical Engineering in Science Citation Index Expanded: A Bibliometric Analysis, Chinese J. Chemi. Eng. 20: 478-488.

Kempers R.D. (2002), Ethical issues in biomedical publications, Ferti. Steri, 77, 883-888.

Khan M.A. and Ho Y.S. (2012), Top-cited articles in environmental sciences: Merits and demerits of citation analysis, Sci. of the Total Environ., 431, 122-127.

Lefaivre K.A., Shadgan B. and O'Brien PJ. (2011), 100 most cited articles in orthopaedic surgery, Clin Orthop Relat Res, 469, 1487-1497.

Loonen M.P., Hage J.J. and Kon M. (2008), Plastic surgery classics: characteristics of 50 top-cited articles in four plastic surgery journals since 1946, Plast recon surg. 121, 320-327.

Moed H.F. (2009), New developments in the use of citation analysis in research evaluation, Arch Immunol Ther Exp (Warsz), 57,13-18.

Nason G.J., Tareen F. and Mortell A. (2013), The top 100 cited articles in urology: An update, Can. Urol. Assoc J. 7, 16- 24.

Norio Ohba M.D., Kumiko Nakao M.D., Yasushi Isashiki M.D. and Ayako Ohba M.A. (2007), The 100 Most Frequently Cited Articles in Ophthalmology Journals, Arch. Ophthalmol, 125, 952 - 960.

Ponce F.A. and Lozano A.M. (2010), Highly cited works in neurosurgery. Part I: the 100 top-cited papers in neurosurgical journals: A review, J Neurosurg, 112, 223-232.

STR, Science Thomas-Reuters. (2014), Available at: http://www.isinet.com Accessed February.

Thyer B.A. (2001), Developing discipline-specific knowledge for social work: Is it possible, J. Social Work Education, 38, 101-13. 